\title{
The Biosynthesis of Steroid Glucuronides in the Testis of the Zebrafish, Brachydanio rerio, and Their Pheromonal Function as Ovulation Inducers
}

\author{
R. van den Hurk, W. G. E. J. Schoonen, G. A. VAN Zoelen, AND \\ J. G. D. LAMBERT \\ Department of Experimental Zoology, Research Group Comparative Endocrinology, University of Utrecht, \\ Padualaan 8, $3584 \mathrm{CH}$ Utrecht, The Netherlands
}

Accepted May 20, 1987

\begin{abstract}
In female zebrafish ovulation could be induced by male holding water, testis homogenates, and testis fractions containing steroid glucuronides. Deglucuronidation of these fractions led to a loss of ovulation-inducing potency, indicating steroid glucuronides as ovulation inducers. The chemical substances were perceived by the recipient females by means of olfaction. Incubation experiments showed the capacity of the testes to synthesize various $\mathrm{C}_{19}$ and $\mathrm{C}_{21}$ steroids and seven different steroid glucuronides, i.e., 17\%,20ß-dihydroxy-4-

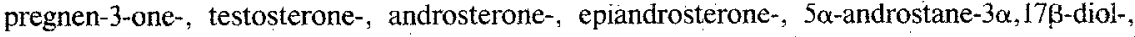
and $5 \alpha$-androstane-3 $3,17 \beta$-diol glucuronide. GC-MS analysis showed the presence of glucuronides of $5 \alpha$-androstane-3 $3,17 \beta$-diol and cholesterol in male holding water, the latter probably originating from the liver. These compounds may be among the steroid glucuronides functioning as ovulation-inducing pheromones. (1) 1987 Academic Press, Inc.
\end{abstract}

Pheromones involved in reproductive processes, such as attraction of the opposite sex, parental behavior, and fertility, are reported to be produced mainly in the gonads or accessory sex organs in fish (Liley 1982; Colombo et al., 1982; Stacey, 1983; Liley and Stacey, 1983). In zebrafish, Brachydanio rerio, intersexual attraction can be caused by extracts of postovulatory zebrafish ovaries (van den Hurk and Lambert 1983; Lambert et al., 1986) and ovulation can be induced by male holding water (Chen and Martinich, 1975).

Little is known about the biochemical nature of these fish pheromones. Algranati and Perlmutter (1981) suggested a cholesterol-ester-like component and van den Hurk and Lambert (1983) pointed to steroid glucuronides as sex attractants for zebrafish. In the guppy, Poecilia reticulata, and the black goby, Gobius jozo, such steroid glucuronides could evoke attraction of conspecifics (Colombo et al., 1982). In the scope of these findings, it might be of bio- technological importance to identify the molecular structures of compounds that can induce ovulation. Administration of these substances might simplify common fish-farming procedures for obtaining viable eggs of fish that do not ovulate spontaneously under culturing conditions.

The present paper deals with the effects of male and female holding water, testicular homogenates, and different fractions of these homogenates on ovulation.

In addition, whether or not ovulation-inducing pheromones are perceived by olfaction was examined. Furthermore, the biosynthesis of steroid glucuronides and steroids in the testes of zebrafish was studied by incubating pieces of testes with $\left[{ }^{3} \mathrm{H}\right]$ pregnenolone and $\left[{ }^{3} \mathrm{H}\right]$ androstenedione, respectively. The incubation products were identified by means of thinlayer chromatography, derivatization, and recrystallization to constant specific activity. A prcliminary analysis of steroid glucuronides in aquarium water containing 
male zebrafish was carried out by means of selected ion monitoring with capillary column gas chromatography-mass spectrometry (GC-MS) to determine the excretion of steroid glucuronides by male zebrafish.

\section{MATERIALS AND METHODS}

\section{Chemicals}

$\left[7-{ }^{3} \mathrm{H}\right]$ Pregnenolone $(8.8 \mathrm{Cj} / \mathrm{mmol})$ and $\left[7-{ }^{3} \mathrm{H}\right]$ androstenedione $(9.7 \mathrm{Ci} / \mathrm{mmol})$ were purchased from Radiochemical Centre (Amersham), and purity was checked by thin-layer chromatography. Nonlabeled steroids and steroid glucuronides were obtained from Steraloids, Makor, and Sigma. Hepes and $\beta$-glucuronidase of Escherichia coli $(100 \mathrm{U} / \mathrm{ml})$ were obtained from Boehringer, Leibovitz L15 medium was from Serva, and $\mathrm{N}, \mathrm{O}$-bis-(trimethylsilyl)acetamide (BSA) and trimethylchlorosilane (TMCS) were from Fluka. All chemicals and solvents (Baker) were of analytical grade. The solvents used for isolation of the steroid glucuronides out of holding water were distilled twice before use.

\section{Animals}

Zebrafish were reared at $25^{\circ}-26^{\circ}$ in aquaria and kept on a light regime of $14 \mathrm{hr}$ light and $10 \mathrm{hr}$ darkness. Under these circumstances, females show a reproductive cycle of 4 to 5 days and males show a continuous spermatogenic cycle and are willing to court females.

For the ovulation test "ovulation-rcady" fcmalcs are needed. To that end, a male and a female were kept together overnight in a 20-liter tank but separated from each other by a net. The next morning when the female is confronted with the male, the male will court the female, resulting in oviposition. Using this method, $50-70 \%$ of the females will ovulate. To bring them into preovulation condition, the ovulated females are stocked for about 1 week in aquaria and then used in the ovulation test. A confrontation of such ovulation-ready females with males again leads to $50-70 \%$ ovulation.

Twenty females were made anosmic by thermocauterizing the nasal epithelium with a tip of $0.1 \mathrm{~mm}$; MS $222(0.02 \%)$ was used as anesthetic. Another group of 20 fish, cauterized between the nostrils, served as controls. After a recovery period of 5 days the females were used in the ovulation test. After the test all females were histologically examined for the presence or absence of intact nasal epithelium. Heads were fixed in Bouin-Hollande, dehydrated in graded ethanol, and embedded via xylene in paraffin. Histolog- ical studies were made with 5 - $\mu$ m-thick sections stained with hemalum-eosin.

\section{Ovulation Tests}

From a central reservoir (20 liters), with an inflow of $\mathrm{Cu}$-free tap water of $1.5 \mathrm{liters} / \mathrm{hr}$, water was siphoned $(0.3$ liter/hr) to five or six aquaria, each containing one female zebrafish in preovulation condition. The water content in these aquaria was maintained constant at 15 liters. Visual contact between the fish was prevented by partitions between the aquaria. Several hours before the start of an experiment, and after termination of it, ovulation was determined by stripping the females by gently pressing the belly.

To test the influence of holding water, eight males or females were placed in the central reservoir for $18 \mathrm{hr}$. All experiments started at $1600 \mathrm{hr}$ and were terminated at $1000 \mathrm{hr}$ the following day. Homogenates of pooled testes and their fractions were diluted in $70 \mathrm{ml}$ distilled water and tested by pumping them $(4 \mathrm{ml} / \mathrm{hr})$ from a cooled container into the central reservoir for $18 \mathrm{hr}$. The amount of tested material for one female always corresponded with testicular material of one male zebrafish.

\section{Statistics}

Comparisons were made between the numbers of ovulated fish in each group and those in the Cu-free tap water group using $2 \times 2$ chi-square tests with an individual error of $P=0.005$, i.e., and experimental error of $P<0.05$. Separately, the number of ovulated anosmic females after addition of male holding water was compared with that of sham-operated females $(P$ $=0.05$ ).

\section{Testicular Fractions}

After anesthesia with MS 222 the testes of several animals were removed, pooled, and homogenized on ice in a Teflon-glass homogenizer with distilled water $\left(0.3 \mathrm{ml} /\right.$ animal). From this homogenate (Fraction $\mathrm{F}_{1}$ ) the lipid material, including the free steroids, was extracted with dichloromethane $(3 \times 10 \mathrm{ml})$. The combined dichloromethane extracts were evaporated and the residue was redissolved in a few drops of propylene glycol and then diluted in $15 \mathrm{ml}$ of distilled water (Fraction $\mathrm{F}_{2}$ ). The remaining water fraction (Fraction $\mathrm{F}_{3}$ ) was evaporated under nitrogen at $40^{\circ}$, redissolved in $2 \mathrm{ml}$ of sodium acetate buffer $(0.1 \mathrm{M}$, pH 6.5), and treated with $100 \mu \mathrm{l}$ of $\beta$-glucuronidase at $37^{\circ}$ for $18 \mathrm{hr}$ under continuous shaking in an air atmosphere. The enzyme reaction was terminated by the addition of $10 \mathrm{ml}$ of dichloromethane, and the deglucuronidated steroids were extracted. The remaining water fraction (Fraction $\mathrm{F}_{4}$ ) might contain steroid con- 
jugates but no steroid glucuronides. A summary of the fractioning is given in Fig. 1.

\section{In Vitro Bioconversion of Steroids}

Incubation procedure. Incubations were carried out with pooled minced testes of 10 animals in Leibovitz15 medium $(1: 4$, w/v) with $15 \mathrm{~m} M$ Hepes containing [7- $\left.{ }^{3} \mathrm{H}\right]$ pregnenolone $(1 \mu \mathrm{Ci})$ or $\left[7-{ }^{3} \mathrm{H}\right]$ androstenedione $(1 \mu \mathrm{Ci})$ dissolved in $44 \mu \mathrm{l}$ propylene glycol. No cofactors were added. The incubations were carried out at $25^{\circ}$ under continuous shaking in an atmosphere of air. The enzyme reactions were terminated after $24 \mathrm{hr}$ by the addition of $1 \mathrm{ml}$ dichloromethane.

Extraction and fractioning. Before extraction with dichloromethane $(3 \times 10 \mathrm{ml}) 25 \mu \mathrm{g}$ of each of the following carriers were added based on pilot studies. lo incubations with pregnenolone, pregnenolone, progesterone, $17 \alpha$-hydroxypregnenolone, $17 \alpha$-hydroxyprogesterone, 5-pregnene-3 $\beta, 17 \alpha, 20 \beta$-triol, $17 \alpha, 20 \beta$-dihydroxy-4-pregnen-3-one, androstenedione, testosterone, 11-ketotestosterone, $11 \beta$-hydroxytestosterone, $5 \alpha$-androstane-3,17-dione, androsterone, and $5 \alpha$-androstane- $3 \alpha, 17 \beta$-diol were added. To incubations with androstenedione, androstenedione, $11 \beta$-hydroxyandrostenedione, 11-ketoandrostenedione, testosterone, 11 ketotestosterone, $11 \beta$-hydroxytestosterone, $5 \alpha$-androstane-3,17-dione, androsterone, and $5 \alpha$-androstane- $3 \alpha, 17 \beta$-diol were added.

The free steroids and steroid conjugates were extracted as described previously. After evaporation, the fractions with the free and the deglucuronidated steroids were both redissolved in dichloromethane: methanol (9:1) and subjected to TLC in system I to separate apolar compounds (triacylglycerols) from steroids. In this system the steroids remain on the baseline, so it is possible to use the same plate for a first separation of the steroids.

Chromatography. TLC and detection of carrier and reference steroids were carried out as described by
Schoonen and Lambert (1986a). The following systems were used: I, toluene-cyclohexane (1:1);II, benzene-ethylacetae (3:1); III, chloroform-ethanol (95:5); IV, diisopropylether-chloroform-hexane (7:2:1); V, benzene-ethanol $(95: 5)$; VI, cyclohexaneethylacetate (1:1); VII, hexane-acetone (2:1); and VIII, ethylacetate-hexane-acetic acid (75:20:5).

Microchemical rcactions, recrystallizations, and measurements of radioactivity were carried ant according to Schoonen and Lambert (1986a).

\section{Isolation and Identification of Steroid Glucuronides from Male. Holding Water}

Chromatography. Baker $\mathrm{C}_{8}$ columns were used for isolation of the steroid glucuronides from male holding water. Ten liters of holding water, in which eight males had been swimming for $18 \mathrm{hr}$, was transferred through the column. After the column was rinsed with distilled water, the steroid glucuronides were eluted with $10 \mathrm{ml}$ of methanol. The eluate was evaporated and the residue treated with $\beta$-glucuronidase, after which the free steroids were derivatized for GC-MS determination.

Derivatization. Trimethylsilyl and oxime-trimethylsilyl derivatives were prepared by reaction first with hydroxylamine hydrochloride (HAH) in pyridine and then with a mixture of BSA and TMCS. The deglucuronidated steroid fraction was transferred with ethanol into a small reaction vial and, following evaporation at $60^{\circ}$ under nitrogen, $200 \mu \mathrm{u}$ of a freshly prepared $2 \% \mathrm{HAH}$ reaction mixture was added. Then the vial was closed, vortexed, and incubated for $1 \mathrm{hr}$ at $100^{\circ}$. Under these conditions keto groups were converted to oximes. Following evaporation, $200 \mu \mathrm{l}$ of a freshly made mixture of BSA:TMCS $(9: 1)$ was added to the residue and incubated for 1 hr at $70^{\circ}$.

After evaporation the residue was dissolved in $2 \mathrm{ml}$ of hexane, and polar compounds (nonsteroid derivatives) were removed by extraction with acetonitrile $(2 \times 0.2 \mathrm{ml})$. Finally the hexane fraction was reduced

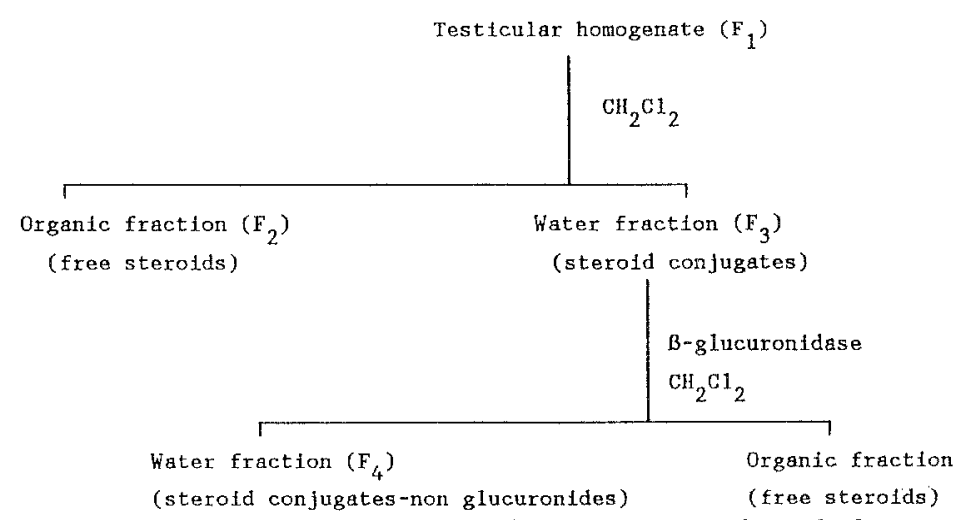

FIG. 1. Fractionation scheme of testicular homogenates of Brachydanio rerio. 
to $50 \mu \mathrm{l}$ and aliquots of $2 \mu \mathrm{l}$ were subjected to GC-MS.

Capillary gas chromatography-mass spectrometry. A Hewlett-Packard 5992 B gas chromatograph-mass spectrometer with a Chrompack fused-silica wallcoated open tubular CP Sil 5 column (film thickness $0.15 \mu \mathrm{m} ; 25 \mathrm{~m} \times 0.34 \mathrm{~mm}$ i.d.) was used with helium as carrier gas at a flow of $2 \mathrm{ml} / \mathrm{min}$. The injection port temperature was $250^{\circ}$ and the oven temperature was set at $160^{\circ}$ and increased $1 \mathrm{~min}$ after injection with a rate of $5 \% \mathrm{~min}$ to $190^{\circ}$, followed by a second increase with a rate of $2 \% \mathrm{~min}$ to $235^{\circ}$. For total ion monitoring with a scan reach of $50-600 \mathrm{~m} / \mathrm{z}$, the multiplier detector was set at $1600 \mathrm{~V}$, and for selected ion monitoring at $2800 \mathrm{~V}$. The mass spectrometer was optimalized for the higher masses $(m / z 414)$ and the obtained mass spectra were nonnormalized spectra.

\section{RESULTS}

\section{Ovulation Tests}

The results of the ovulation induction tests are summarized in Table 1. Control experiments carried out with $\mathrm{Cu}$-free tap water resulted in only one ovulated female out of 18 animals. Male holding water, however, does promote ovulation significantly, whereas female holding water does not. Fifty percent of the sham-operated fish had ovulated after introduction of male holding water, whereas under the same conditions only 3 out of 20 anosmic females ovulated. Histological examination of these 3 fish revealed that the olfactory epithelium was still partly intact and the nostrils were open. In all other anosmic females the skin epithelium had proliferated and closed the nostrils completely. After administration of testes homogenates (Fraction $F_{1}$ ) and testicular steroid conjugate fraction (Fraction $\mathrm{F}_{3}$ ), significantly more females ovulated than in the control group. Testicular Fractions $F_{2}$, with the free steroids, and $F_{4}$, containing the steroid conjugates without glucuronides, did not significantly enhance the percentage of ovulation.

Ovaries of nonovulated females contain a mixed population of follicles, most of which are stage 3 follicles (van Ree, 1976), containing oocytes in postvitellogenesis with a central germinal vesicle and a diameter up to $800 \mu \mathrm{m}$. Ovulated females in addition have postovulatory follicles. Oocyles with a migrating germinal vesicle, or with the germinal vesicle broken down, were absent from all ovaries examined.

\section{In Vitro Bioconversion of Steroids}

Incubation with $\left[{ }^{3} \mathrm{H}\right]$ pregnenolone. After extraction with dichloromethane about $92 \%$ of the radioactivity was present in the

TABLE 1

Effects of Zebrafish Holning Water and Testicular Fractions on Oviti.ation In Zfirrafish

\begin{tabular}{llccc}
\hline \multicolumn{1}{c}{ Test material } & \multicolumn{1}{c}{ Females } & $\begin{array}{c}\text { Number of } \\
\text { ovulated } \\
\text { fish }\end{array}$ & $\begin{array}{c}\text { Total } \\
\text { number } \\
\text { of fish }\end{array}$ & $\begin{array}{c}\text { Ovulation } \\
\text { percentage }\end{array}$ \\
\hline Cu-free tap water & Intact & 1 & 18 & 5.6 \\
Male holding water & Intact & 11 & 16 & $68.8^{*}$ \\
Female holding water & Intact & 4 & 15 & 26.7 \\
Male holding water & Sham operated & 10 & 20 & $50.0^{*}$ \\
Male holding water & Anosmic & 3 & 20 & $15.0^{* *}$ \\
Testicular Fraction $\mathrm{F}_{1}{ }^{a}$ & Intact & 9 & 17 & $52.9^{*}$ \\
Testicular Fraction $\mathrm{F}_{2}{ }^{a}$ & Intact & 1 & 15 & 6.7 \\
Testicular Fraction $\mathrm{F}_{3}{ }^{a}$ & Intact & 9 & 15 & $60.0^{*}$ \\
Testicular Fraction $\mathrm{F}_{4}{ }^{a}$ & Intact & 4 & 15 & 26.7 \\
\hline
\end{tabular}

\footnotetext{
${ }^{a} \mathrm{~F}_{1}$, testicular homogenate; $\mathrm{F}_{2}$, free steroids; $\mathrm{F}_{3}$, steroid conjugates; $\mathrm{F}_{4}$, steroid conjugates without glucuronides.

${ }^{*} P=0.05$ compared with Cu-free tap water group.

** $P=0.05$ compared with sham-operated females.
} 
organic fraction. The first separation was done by TLC in system II $(3 \times)$ and resulted in eight radioactive areas $(\mathrm{A}-\mathrm{H})$ corresponding to the following carriers: (A) 11-ketotestosterone, $17 \alpha, 20 \beta$-dihydroxy-4pregnen-3-one, and 5-pregnene-3 $\beta, 17 \alpha$, $20 \beta$-triol; (B) 11 $\beta$-hydroxyandrostenedione; (C) 11-ketoandrostenedione, testosterone, and $5 \alpha$-androstane- $3 \alpha, 17 \beta$-diol; (D) $17 \alpha$-hydroxypregnenolone and $17 \alpha$-hydroxyprogesterone; (E) androsterone; (F) androstenedione and pregnenolone; and (G) $5 \alpha$-androstane-3,17-dione. Area $\mathrm{H}$ is present on the front line.

After TLC in different systems, derivatization, and recrystallization to constant specific activity (Table 2), it appeared that the tritium activity in the different areas was caused by (A) 11-ketotestosterone, $17 \alpha$ $20 \alpha$-dihydroxy-4-pregnen-3-one, $17 \alpha, 20 \beta$ dihydroxy-4-pregnen-3-one, and 5-pregnene-3 $\beta, 17 \alpha, 20 \beta$-triol; (B) 11 $\beta$-hydroxyandrostenedione; (C) 11-ketoandrostenedione and testosterone; (D) $17 \alpha$-hydroxypregnenolone and $17 \alpha$-hydroxyprogesterone; (E) androsterone and epiandrosterone; (F) pregnenolone and androstcnedionc; (G) $5 \alpha$ androstane-3,17-dione; and $(\mathrm{H})$ a steroid ester, which was identified as a pregnenolone ester.

The evidence of the presence of four of these steroids, i.e., $17 \alpha, 20 \alpha$-dihydroxy-4pregnen-3-one, 11-ketotestosterone, androsterone, and epiandrosterone, is based only on their chromatographic behavior. $17 \alpha, 20 \alpha$-Dihydroxy-4-pregnen-3-one was identified indirectly by eliminating other possibilities based on derivatization and $R_{f}$ values (Schoonen et al., 1987b). The synthesis of 11 -ketotestosterone, androsterone, and epiandrosterone was confirmed after incubations with $\left[{ }^{3} \mathrm{H}\right]$ androstenedione.

The water fraction after $\beta$-glucuronidase treatment, extraction, and separation of the free steroids by TLC in system II $(3 \times)$ after scanning revealed only two radioac- tive areas. These areas corresponded with areas $A$ and $C$ of the organic fraction. Rechromatography, derivatization, and recrystallization (Table 2) demonstrated that the radioactivity originated from $17 \alpha, 20 \beta$ dihydroxy-4-pregnen-3-one, 5-pregnene$3 \beta, 17 \alpha, 20 \beta$-triol, testosterone, and $5 \alpha$-androstane- $3 \alpha, 17 \beta$-diol.

The quantitative data of the yields of the steroids are also given in Table 2. It appears that after an incubation of $24 \mathrm{hr}$ the main products are $17 \alpha$-hydroxypregnenolone, $17 \alpha$-hydroxyprogesterone, $17 \alpha, 20 \alpha$-dihydroxy-4-pregnen-3-one, and androstenedione.

Incubation with $\left[{ }^{3} \mathrm{H}\right]$ androstenedione. After extraction, the organic fraction contained $87 \%$ of the radioactivity. TLC in system II $(3 \times)$ and scanning made it possible to distinguish six different radioactive areas. These areas were characterized by the following carriers: (A) 11-ketotestosterone; (B) 11ß-hydroxyandrostenedione; (C) 11-ketoandrostenedione, testosterone, and $5 \alpha$-androstane- $3 \alpha, 17 \beta$-diol; (D) androsterone; (E) androstenedione; and (F) $5 \alpha$-androstane-3,17-dione.

After TLC in several systems, derivatization, and finally recrystallization to constant specific activity (Table 2), it could be demonstrated that tritium activity in areas A-F belonged to the following steroids: (A) 11-ketotestosterone; (B) 11ß-hydroxyandrostenedione; (C) 11-ketoandrostenedione, testosterone, $5 \alpha$-androstane- $3 \alpha, 17 \beta$ diol, and $5 \alpha$-androstane-3 $\beta ; 17 \beta$-diol; (D) androsterone and epiandrosterone; (E) androstenedione; and (F) $5 \alpha$-androstane-3,17dione.

Glucuronidase treatment of the water fraction (13\% of the total radioactivity), followed by extraction with dichloromethane and chromatography of the organic fraction by TLC in system 1 ( $(3 \times)$, showed the presence of two radioactive areas corresponding to areas $C$ and $D$ of the organic fraction. After TLC in several 


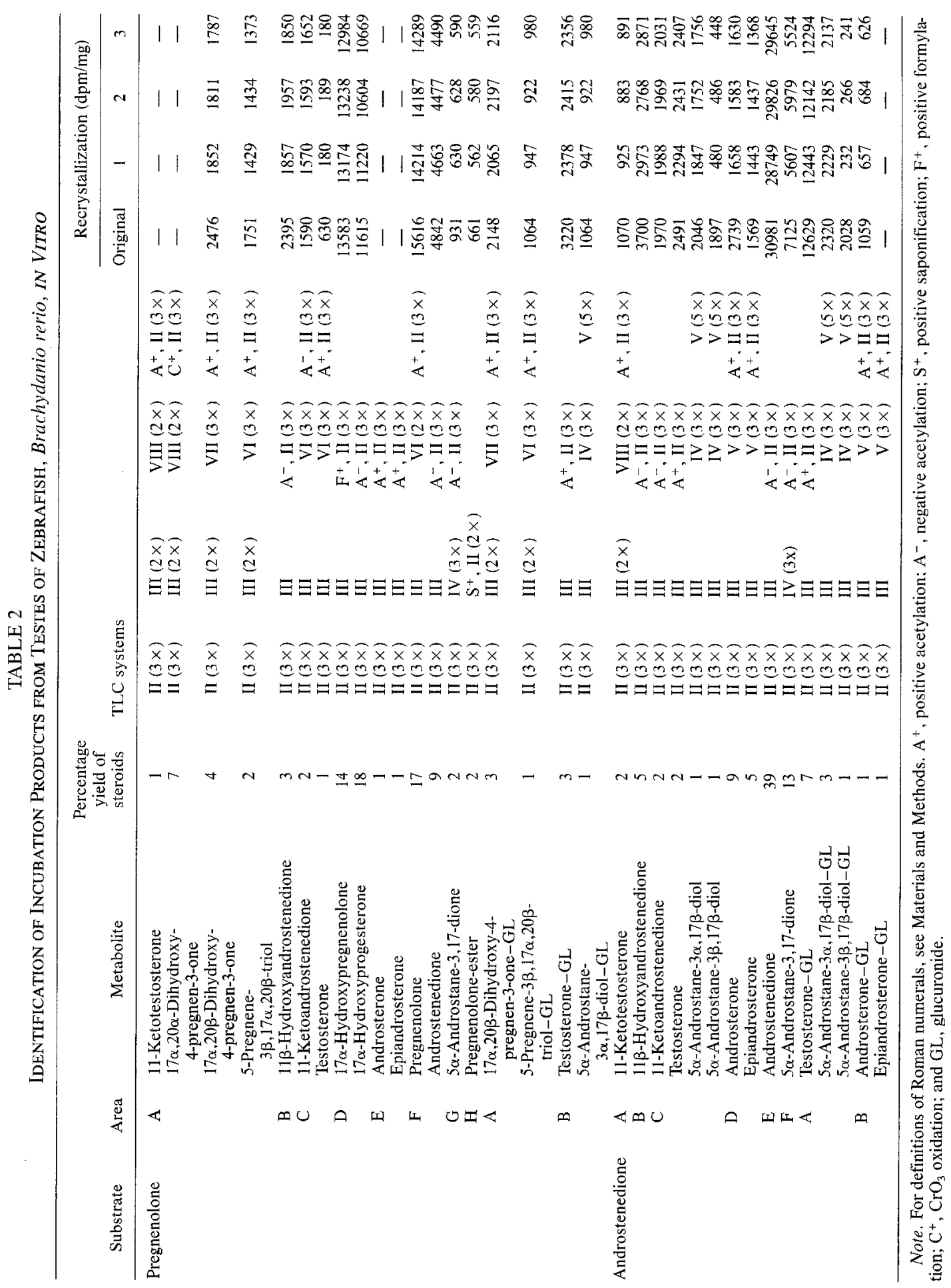


systems, derivatization, and recrystallization, the following steroids were identified: testosterone, $5 \alpha$-androstane- $3 \alpha, 17 \beta$-diol, $5 \alpha$-androstane- $3 \beta, 17 \beta$-diol, androsterone, and epiandrosterone (Table 2).

The quantitative data of these steroids, obtained from duplicate incubations, are also given in Table 2. The main products appeared to be $5 \alpha$-androstane-3,17-dione, androsterone, epiandrosterone, and the glucuronide of testosterone.

\section{Isolation and Identification of Steroid \\ Glucuronides from Male Holding Water}

The steroid glucuronides were isolated from male holding water by reversed-phase chromatography and then treated with $\beta$ glucuronidase. The deglucuronidated fraction was subjected to GC-MS analysis, first to total ion monitoring and then to selected ion monitoring (SIM). The compounds looked for were all steroids which were found as glucuronides after incubation of testes material with $\left[{ }^{3} \mathrm{H}\right]$ pregnenolone or $\left[{ }^{3} \mathrm{H}\right]$ androstenedione, i.e., $17 \alpha, 20 \beta$ dihydroxy-4-pregnen-3-one, 5-pregnene$3 \beta, 17 \alpha, 20 \beta$-triol, testosterone, $5 \alpha$-androstane- $3 \alpha, 17 \beta$-diol, $5 \alpha$-androstane$3 \beta, 17 \beta$-diol, androsterone, and epiandrosterone. With spectral analysis none of these steroids could be identified. Cholesterol, however, was found by this procedure. A full spectrum of cholesterol-trimethylsilane (TMS) could be detected at a retention time of $35.4 \mathrm{~min}$, comparable to standard cholesterol-TMS (Fig. 2). With the SIM analysis only $5 \alpha$-androstane$3 \alpha, 17 \beta$-diol could be demonstrated. The mass spectrum of standard $5 \alpha$-androstane$3 \alpha, 17 \beta$-diol-diTMS (MW 436.3) has typical fragment ions with $\mathrm{m} / \mathrm{z} 436.6\left(\mathrm{M}^{+}\right), \mathrm{m} / \mathrm{z}$ 421.3 $\left(\mathrm{M}^{+}-\mathrm{CH}_{3}\right)$, and $m / z .346 .3\left(\mathrm{M}^{+}\right.$OTMS) (Fig. $3 \mathrm{~A}$ ). The retention time is $17.8 \mathrm{~min}$. The theoretical abundance ratio for the ions $\mathbf{M}^{+}, \mathbf{M}^{+}+1, \mathrm{M}^{+}+2$, i.e., 436.3, 437.3 , and 438.3 , is $100: 38: 14$. With SIM analysis these characteristic fragment ions
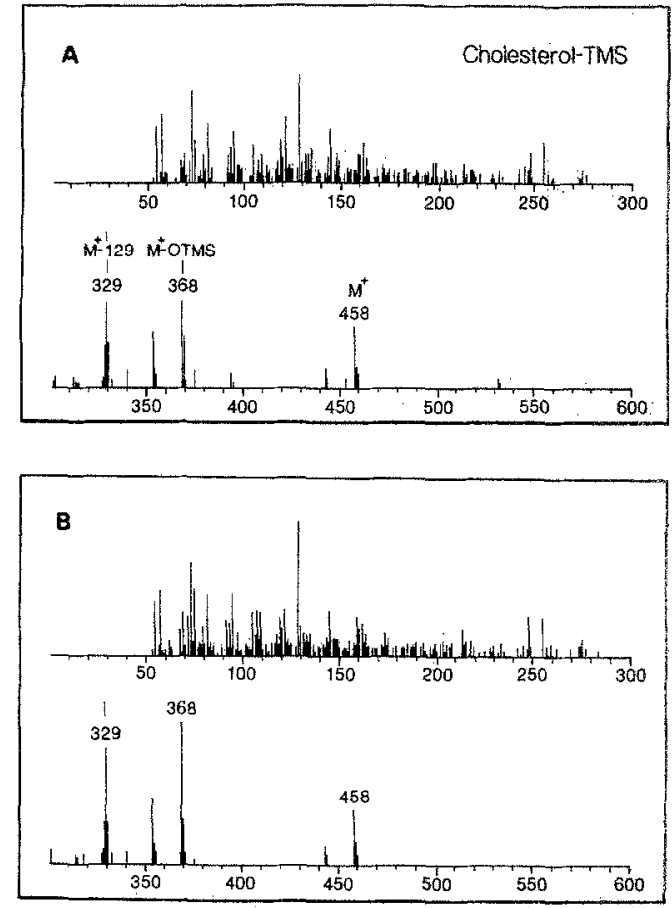

FIG. 2. (A) Mass spectrum (nonnormalized) of cholesterol-TMS. The molecular ion and particular mass fragments are $m / z 458, m / z 368$, and $m / z 329 . \mathrm{M}^{+}$, molecular ion; OTMS, O-trimethylsilyl. (B) Mass spectrum (nonnormalized) of a compound isolated from the steroid glucuronide fraction of male holding water of Brachydanio rerio after treatment with $\beta$-glucuronidase and derivatization with particular ions with $m / z$ $458, m / z 368$, and $m / z 329$.

were also monitored in the extract of male holding water at a retention time of exactly $17.8 \mathrm{~min}$. (Fig. 3B). The abundance ratio for the ions $M, M+1, M+2$ was 100:36:15. This indicates that at least $5 \alpha$ androstane- $3 \alpha, 17 \beta$-diol-glucuronide was present in the male holding water.

\section{DISCUSSION}

The present data indicate that male holding water is much more potent in inducing ovulation (about 70\%) in zebrafish than female holding water (27\%). The value obtained with male holding water was significantly different from the results with tap water, whereas that of female holding water was higher but not significantly different. 
The percentage of ovulation due to male holding water falls within the range of ovulation values $(50-70 \%)$ that occur when a male is brought together with a nonovulated female. The ovulation-inducing effect of male holding water confirms previous data of Chen and Martinich (1975). These authors, however, achieved better results, i.e., $100 \%$ ovulation, as a consequence of different experimental procedures. In their experiments, for example, female zebrafish were allowed two successive opportunities to ovulate, and fish were only counted as nonovulated females when afterward they were able to ovulate in the presence of a male.

Histological examination of the ovaries of nonovulated females demonstrates the presence of oocytes with central germinal vesicles only; thus oocytes with germinal vesicle migration and/or germinal vesicle breakdown were absent. Anosmic fish with
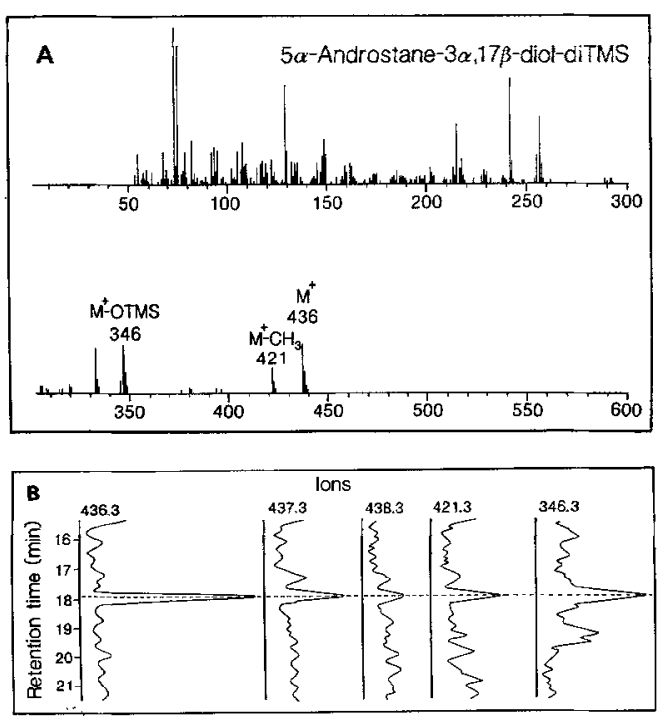

FIG. 3, (A) Mass spectrum (nonnormalized) of $5 \alpha-$ androstane-3 $\alpha, 17 \beta$-diol (diTMS). The molecular ion with $m / z 436$ and the mass ions with $m / z 421$ and $m / z$ 346 are indicated. $\mathrm{M}^{+}$, molecular ion; OTMS, $O$-trimethylsilyl. (B) SIM analysis of the characteristic ions $\mathrm{m} / \mathrm{z} 436.3 \mathrm{~m} / \mathrm{z} 437.3, \mathrm{~m} / \mathrm{z} 438.3, \mathrm{~m} / \mathrm{z} 421.3$, and $\mathrm{m} / \mathrm{z}$ 346.3 of the steroid glucuronide fraction of male holding water of Brachydanio rerio after treatment with $\beta$-glucuronidase and derivatization. closed nostrils do not ovulate after introduction of male holding water. The few fish of the anosmic group that ovulated after addition of this holding water had partly intact olfactory epithelia and open nostrils, and thus were apparently able to smell. The present data indicate that ovulation-inducing male pheromones of zebrafish are perceived by olfaction. This method of chemoreception corresponds to that of sex attractants in B. rerio (van den Hurk and Lambert, 1983) and other teleost fish, i.e., Bathygobius soporator (Tavolga, 1976), Carassius auratus (Partridge et al., 1976), and Plecoglossus altivelus (Honda, 1979).

In view of the ovulation-inducing effect of male holding water, the testis is a good candidate for the production of sex pheromones. Indeed, experiments with testis homogenates of zebrafish show a strong ovulation response (52.9\%). The steroid conjugate fraction of this homogenate also results in a high percentage of ovulated females $(60 \%)$, whereas the free steroid fraction is unable to evoke such an effect. After $\beta$-glucuronidase treatment, the steroid conjugate fraction looses a great deal of its ovulation-promoting effect. This points to glucuronidated compounds, most likely steroid glucuronides, as the active chemical cues. These findings correspond with those of the few studies concerning the nature of sex attractants in fish. In zebrafish, steroid glucuronides produced by postovulatory ovaries evoked attraction of conspecific males (van den Hurk et al., 1982, van den Hurk and Lambert, 1983). In G. jozo, etiocholanolone glucuronide formed in the mesorchial gland of the male has an attractive effect (Colombo et al., 1980, 1982), and the same compound has been shown to be attractive for male $C$. auratus, and $P$. reticulata (Colombo et al., 1982).

Incubation studies with tritium-labeled pregnenolone and androstenedione have demonstrated that the testis of the zebrafish is able to produce steroid glucuronides apart from the more common $\mathrm{C}_{21}$ and $\mathrm{C}_{19}$ 
steroids. Pregnenolone will first of all be converted into $17 \alpha$-hydroxypregnenolone and $17 \alpha$-hydroxyprogesterone. From $17 \alpha-$ hydroxyprogesterone onward, two main steroidogenic pathways can be distinguished. The first one runs via a $\mathrm{C}_{20}$ oxidoreductase to $17 \alpha, 20 \alpha$-dihydroxy-4-pregnen-3-one and $17 \alpha, 20 \beta$-dihydroxy-4-pregnen-3-one, and to a glucuronide of the latter. Apart from these products, a conversion into 5 -pregnene- $3 \beta, 17 \alpha, 20 \beta$-triol and its glucuronide could also be demonstrated. This conversion, however, must in all probability be considered as artificial, because it may be the result of a temporary accumulation of $17 \alpha$-hydroxypregnenolone.

The second route runs via a $C_{17-20}$ lyase to the formation of androstenedione and is followed by a conversion into testosterone and its glucuronide as well as into 11-oxygenated androgens, i.e., 11 $\beta$-hydroxyandrostenedione, 11-ketoandrostenedione, and 11 -ketotestosterone. Also, a $5 \alpha$-reduction of androstenedione may occur, resulting in the synthesis of $5 \alpha$-androstane3,17-dione, androsterone, epiandrosterone, and the glucuronide of $5 \alpha$-androstane$3 \alpha, 17 \beta$-diol. Incubations with tritiated androstenedione confirmed these conversions and moreover showed the synthesis of the glucuronides of $5 \alpha$-androstane- $3 \alpha, 17 \beta$-diol, androsterone, and epiandrosterone.

These data indicate that the testis of zebrafish is able to synthesize, apart from unconjugated $\mathrm{C}_{19}$ and $\mathrm{C}_{21}$ steroids, at least six or seven steroid glucuronides. Only a few steroid glucuronides have been demonstrated in the testis of teleosts. Testosterone glucuronide is found to be produced by the testes of rainbow trout Salmo gairdneri (Hews and Kime, 1978) and goldfish, C. auratus (Kime, 1980). The $5 \alpha$-reduced steroid glucuronides, however, have so far not been described as being synthesized by teleost testes, whereas $5 \beta$-reduced steroid glucuronides have been found among the products of steroidogenesis in the testes of the black goby, G. jozo (Colombo et al., 1977) and African catfish, Clarias gariepinus (Schoonen et al., 1987b). Concerning African catfish, it must be mentioned that the seminal vesicle is the main source of steroid glucuronides (Schoonen and Lambert, 1986b, Schoonen et al., 1987a). The formation of $17 \alpha, 20 \beta$-dihydroxy-4-pregnen-3-one by the testes has previously been described in some other teleosts, i.e., the rainbow trout, $S$. gairdneri (Arai and Tamaoki, 1967; Kime 1979; Depếche and Sire, 1982), and the African catfish, C. gariepinus (Schoonen and Lambert 1986a; Schoonen et al., 1987b). According to Ueda et al. (1984) it is the sperm that is involved in the final synthesis of $17 \alpha, 20 \beta$-dihydroxy-4-pregnen-3-one. The synthesis of the glucuronide of this steroid is a new finding.

Whether all steroid glucuronides produced by the testis of the zebrafish have a pheromonal function remains to be investigated. Until now only one of these compounds $(5 \alpha$-androstane-3 $3 \alpha, 17 \beta$-diol-glucuronide) could be detected in male holding water by GC-MS analysis. Cholesterol glucuronide, also demonstrated in this holding water, probably originates from the liver, although a testicular origin cannot be excluded.

\section{ACKNOWLEDGMENTS}

The authors thank Prof. Dr. P. G. W. J. van Oordt for his encouraging interest and for critically reviewing the manuscript. Thanks are also due to $\mathrm{Ms}$. J. C. M. Granneman for her technical assistance, the department of Image Processing and Graphic Design for making the figures, and Miss M. H. van Hattum for typing the manuscript.

\section{REFERENCES}

Algranati, F. D., and Perlmutter, A. (1981). Attraction of zebrafish, Brachydanio rerio, to isolated and partially purified chromatographic fractions. Environ. Biol. Fish. 6, 31-38.

Arai, R., and Tamaoki, B. (1967). Steroid biosynthesis in vitro by testis of rainbow trout, Salmo gaird neri. Gen. Comp. Endocrinol. 8, 305-313. 
Chen, L. C., and Martinich. R. L. (1975). Pheromonal stimulation and metabolic inhibition of ovulation in the zebrafish, Brachydanio rerio. Fish Bull. 73, 889-894.

Colombo, L., Colombo-Belvédère, P., Marconato, A., and Bentivegna, F. (1982). Pheromones in teleost fish. In "Proceedings of the International Symposium on Reproductive Physiology of Fish" (C. J. J. Richter and H. J. Th. Goos, Eds.), pp. 84-94. Wageningen, The Netherlands.

Colombo, L., Colombo-Belvédère, P., and Pilati, A. (1977). Biosynthesis of free and conjugated $5 \beta$-reduced androgens by testes of the black goby, Gobius jozo L. Boll. Zool. 44, 131-134.

Colombo, L., Marconato, A., Colombo-Belvédère, P., and Frisco, C. (1980). Endocrinology of teleost reproduction: A testicular steroid pheromone in the black goby, Gobius jozo L. Biol. Zool. 47, 355-364.

Depêche, 1., and Sire, O. (1982). In vitro metabolism of progesterone and $17 \alpha$-hydroxyprogesterone in the testis of the rainbow trout, Salmo gairdneri at different stages of spermatogenesis. Reprod. Nutr. Dev. 22, 427-438.

Hews, E. A., and Kime, D. E. (1978). Formation of testosterone glucuronide by testes of the rainbow, trout, Salmo gairdneri. Gen. Comp. Endocrinol. 34, 116-119.

Honda, H. (1979). Female sex pheromone of the ayu, Plecoglossus altivelis, involved in courtship behaviour. Bull. Japan. Soc. Sci. Fish. 45, $1375-1380$.

Kime, D. E. (1979). The effect of temperature on the testicular steroidogenic enzymes of the rainbow trout, Salmo gairdneri. Gen. Comp. Endocrinol. 39, 290-296.

Kime, D. E. (1980). Androgen biosynthesis by the testes of the goldfish, Carassius auratus, in vitro: The effect of temperature on the formation of steroid glucuronides. Gen. Comp. Endocrinol. 41, 164-172.

Lambert, J. G. D., van den Hurk, R., Schoonen, W. G. E. J., Resink, J. W., and van Oordt, P. G. W. J. (1986). Gonadal steroidogenesis and the possible role of steroid glucuronides as sex pheromones in two species of teleosts. Fish Physiol. Biochem. 2, 101-107.

Liley, N. R. (1982). Chemical communication in fish. Canad. J. Fish. Aquat. Sci. 39, 22-35.

Liley, N. R., and Stacey, N. E. (1983). Hormones, pheromones, and reproductive behaviour in fish. In "Fish Physiology" (W. S. Hoar, D. J. Randall, and E. M. Donaldson, Eds.), Vol. 9 B, pp. 1-64. Academic Press, New York.

Partridge, B. L., Liley, N. R., and Stacey, N. E. (1976). The role of pheromones in the sexual be- haviour of the goldfish. Anim. Behav. 24, $291-299$.

Schoonen, W. G. E. J., Granneman, J. C. M., Lambert, J. G. D., Viveen, W. J. A. R., and van Oordt, P. G. W. J. (1987a). Quantitative studies of steroid bioconversions in the seminal vesicles of spawning male African catfish, Clarias gariepinus (Burchell), under natural conditions and of nonspawning catfish under natural and fish farm conditions. Comp. Biochem. Physiol., in press.

Schoonen, W. G. E. J., and Lambert, J. G. D. (1986a). Steroid metabolism in the testes of the African catfish, Clarias gariepinus (Burchell), during the spawning season, under natural conditions and kept in ponds. Gen. Comp. Endocrinol. 61, 40-52.

Schoonen, W. G. E. J., and Lambert, J. G. D. (1986b). Steroid metabolism in the seminal vesicles of the African catfish, Clarias gariepinus (Burchell), during the spawning season, under natural conditions, and kept in ponds. Gen. Comp. Endocrinol. 61, 355-367.

Schoonen, W. G. E. J., Lambert, J. G. D., Resink, J. W., Viveen, W. J. A. R., and van Oordt, P. G. W. J. (1987b). A quantitative study of steroid bioconversion in the testes of the African catfish, Clarias gariepinus (Burchell), under natural spawning and natural and cultivated nonspawning conditions. Endocr. 112, 323-332.

Sokal, R. R., and Rohlf, F. J. (1969). "Biometry: The Principles and Practice of Statistics in Biological Research." Freeman, San Francisco.

Stacey, N. E. (1983). Hormones and pheromones in fish sexual behavior. BioScience 33, 552-556.

Tavolga, W. N. (1976). Chemical stimuli in reproductive behaviour in fish communication. Experientia 32, 1093-1095.

Ueda, H., Kambegawa, A., and Nagahama, Y. (1984). In vitro 11 -ketotestosterone and $17 \alpha, 20 \beta$-dihydroxy-4-pregnen-3-one production by testicular fragments and isolated sperm of rainbow trout, Salmo gairdneri. J. Exp. Zool. 231, 435-439.

van den Hurk, R., and Lambert, J. G. D. (1983). Ovarian steroid glucuronides function as sex pheromones for male zebrafish, Brachydanio rerio. Canad. J. Zool. 61, 2381-2387.

van den Hurk, R., 't Hart, L. A., Lambert, J. G. D., and van Oordt, P. G. W. J. (1982). On the regulation of sexual behavior of male zebrafish, $\mathrm{Bra}$ chydanio rerio. Gen. Comp. Endocrinol. 46, 403 (Abstract).

van Ree, G. E. (1976). Effects of methallibure (I.C.I. 33,828 ) and ovine luteinizing hormone on the ovary and the pituitary of the female zebrafish, Brachydanio rerio. Proc. Kon. Ned. Akad. Wetensch. C79, 150-170. 